\title{
Infliximab Therapy in Iraqi Patients with Moderate to Severe Psoriasis
}

\author{
Hayder R. Al-Hamamy ${ }^{*}$, Ihsan A. Al-Turfy², Farah S. Abdul-Reda ${ }^{3}$ \\ ${ }^{1}$ Scientific Council of Dermatology \& Venereology, Iraqi Board for Medical Specializations, Baghdad, Iraq \\ ${ }^{2}$ College of Medicine University of Baghdad, Baghdad, Iraq \\ ${ }^{3}$ Department of Dermatology \& Venereology, Baghdad Teaching Hospital, Baghdad, Iraq \\ Email: ${ }^{*}$ hayder317@gmail.com, dr ihssanalturfy@yahoo.com, dr.farah248@yahoo.com
}

Received 7 April 2015; accepted 5 June 2015; published 9 June 2015

Copyright (C) 2015 by authors and Scientific Research Publishing Inc.

This work is licensed under the Creative Commons Attribution International License (CC BY).

http://creativecommons.org/licenses/by/4.0/

(c) () D Open Access

\begin{abstract}
Background: Tumor necrosis factor alpha (TNF- $\alpha$ ) is a proinflammatory cytokine which plays a critical role in the pathogenesis of psoriasis. Infliximab is an anti-TNF- $\alpha$ drug widely used for the treatment of psoriasis. Objectives: To assess the efficacy and safety of infliximab in Iraqi patients with moderate-to-severe psoriasis. Patients and Methods: In this therapeutic, single-center study, a total of 23 patients with moderate-to-severe psoriasis resistant to conventional treatments were enrolled to receive infusions of infliximab $5 \mathrm{mg} / \mathrm{kg}$ at weeks 0,2 , and 6 , then every 8 weeks for at least 22 weeks. Psoriasis Area and Severity Index(PASI), Body Surface Area (BSA) and Dermatology Life Quality Index (DLQI) were calculated at each visit to assess the response to treatment and all side effects were recorded. Results: PASI score was reduced from a mean \pm SD of $17.41 \pm 8.53$ before treatment to $2.44 \pm 2.68$ after 22 weeks. At week $22,84 \%$ of patients achieved PASI 75, $42 \%$ achieved PASI 90 and $28 \%$ achieved complete clearance. BSA and DLQI score were reduced from a mean \pm SD of $35.69 \pm 22.44$ and $20.04 \pm 4.68$ before treatment to $3.52 \pm 4.94$ and $3.87 \pm 5.60$ after 22 weeks, respectively. Pruritus, boils, infusion reactions were recorded and relapse during treatment was found in 3 patients. Conclusion: Infliximab monotherapy is highly effective in the treatment of moderate-to-severe psoriasis, with rapid onset of action and relatively low side effects.
\end{abstract}

\section{Keywords}

Psoriasis, TNF- $\alpha$, Infliximab

\section{Introduction}

Psoriasis is a common chronic and immunomediated skin disease which typically follows a relapsing and remitting course [1]. Psoriasis affects approximately 2\% - 3\% of world's population [2].

\footnotetext{
${ }^{*}$ Corresponding author.
}

How to cite this paper: Al-Hamamy, H.R., Al-Turfy, I.A. and Abdul-Reda, F.S. (2015) Infliximab Therapy in Iraqi Patients with Moderate to Severe Psoriasis. Journal of Cosmetics, Dermatological Sciences and Applications, 5, 78-85. 
The proinflammatory cytokine tumor necrosis factor alpha (TNF- $\alpha$ ) plays an important role in the pathogenesis of psoriasis [3] [4].

The TNF- $\alpha$ antagonist infliximab, a chimeric monoclonal IgG1 antibody, has been shown to be highly effective for the treatment of psoriasis. In addition to blocking soluble TNF- $\alpha$, infliximab is also capable of binding transmembrane TNF- $\alpha$, resulting in complement fixation and antibody-mediated cytolysis [5]-[7]. Given infliximab's characteristic rapid onset of action and high response rates, it is recommended when rapid disease control is required in unstable conditions such as erythrodermic or pustular psoriasis [5].

The significant reduction in quality of life and the psychosocial disability suffered by patients underline the need for prompt, effective treatment, and long-term disease control.

Therefore the present study was designed to evaluate the efficacy and safety of infliximab in Iraqi patients with moderation to severe psoriasis.

\section{Patients and Methods}

This phase IV, prospective, therapeutic, single centerinterventional study was carried out at the Department of Dermatology and Venereology, Baghdad Teaching Hospital, from May 2013 to July 2014. This is the largest hospital in Baghdad city with more than 1000 beds.

Formal consent was taken from each patient after full explanation about the nature of the study and an ethical approval was granted by the Scientific Council of Dermatology \& Venereology-Iraqi Board for Medical Specializationson March 2013.

Adult patients with chronic moderate to severe psoriasis resistant to conventional systemic treatments were included in this study. The exclusion criteria include pregnant or lactating women, patients younger than 18 years, those with severe hepatic, renal, hematological or other systemic disorders, moderate-to-severe heart failure, immunosuppression, history or risk of serious infection, lymphoproliferative, demyelinating disease or active or latent tuberculosis and positive virology for hepatitis or HIV infection.

Psoriasis Area and Severity Index (PASI) score was calculated according to dermnet [8]. Body Surface Area (BSA) was calculated as the patient's hand, including the palm, fingers and thumb represent roughly $1 \%$ of the body's surface [9]. Dermatology Life Quality Index (DLQI) score was calculated according to Cardiff University Dermatology Department work group [10].

Depending on the above mentioned parameters for measuring severity of psoriasis, patients with moderate to severe psoriasis in the present work were defined as having PASI $>10$, BSA $>10$ and/or DLQI $>10$.

They received intravenous infliximab infusion in a dose of $5 \mathrm{mg} / \mathrm{kg}$ to be repeated at 2, 6 and then every 8 weeks there after according to British Association of Dermatologists' guidelines for the treatment of psoriasis with biologics [11].

Clinical response was assessed by calculating PASI scores, BSA and DLQI score at baseline and at each infusion session. In patients with pustular psoriasis PASI score is not applicable so BSA was depended for evaluation. Safety was assessed by measurement of routine laboratory parameters and reporting of adverse events at all study visits.

Student $t$-test was used to compare the results with $\mathrm{p}$ values $<0.05$ were considered to indicate statistical significance.

\section{Results}

Twenty three patients completed at least 22 weeks of treatment, 21 patients had plaque psoriasis and 2 patients had generalized pustular psoriasis. Seventeen $(73.91 \%)$ were males and 6 (26.08\%) were females. Their ages ranged from $20-62$ years with a mean \pm SD of $39.69 \pm 10.57$ years. The duration of their disease ranged from 1 - 33 years with a mean \pm SD of $12.39 \pm 8.19$ years, 12 patients (52\%) had negative family history of psoriasis and 11 (47\%) had positive family history. The patients had no other diseases and they were not on any other medications. Their mean baseline PASI score ranged from $6.4-31.9$ with a mean \pm SD of $17.41 \pm 8.53$. Their baseline BSA\% ranged from $6 \%-75 \%$ with a mean \pm SD of $35.69 \pm 22.44$. Baseline DLQI score was ranged from 13 - 28 with a mean \pm SD of $20.04 \pm 4.68$ (see Figures 1-3).

\subsection{PASI Score}

PASI score was reduced from a mean \pm SD of $17.41 \pm 8.53$ before treatment to $9.75 \pm 6.34$ at 2 weeks, to $4.26 \pm$ 


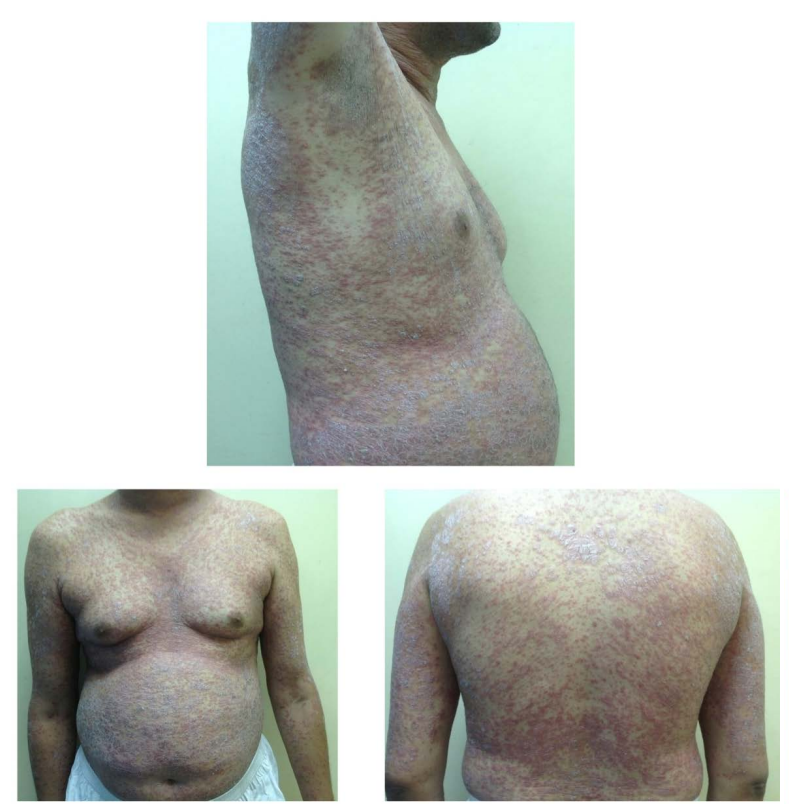

(a)

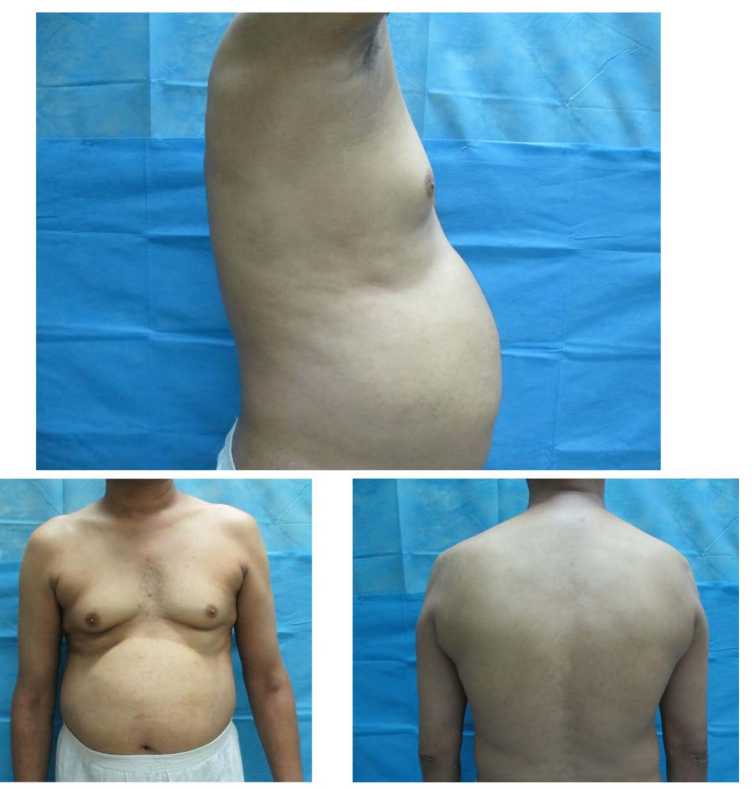

(b)

Figure 1. Forty-one year old male with generalized plaque psoriasis for 2 years. (a) Before treatment; (b) after 6 weeks of treatment.

4.01 at 6 weeks, to $3.39 \pm 3.46$ at 14 weeks and to $2.44 \pm 2.68$ at 22 weeks of treatment.

Table 1 shows comparison of PASI score at each visit with the previous visit with p-values.

The reduction in PASI score was calculated as percent of the original PASI. It was 43.99\%, 75.53\%, 80.52\% and $85.98 \%$ after 2, 6, 14 and 22 weeks of treatment respectively.

After 14 wks of treatment, $90 \%$ of patients with plaque psoriasis achieved $>50 \%$ reduction in PASI score (PASI 50 ), $71 \%$ of patients achieved $>75 \%$ reduction (PASI 75 ), 33\% of patients achieved $>90 \%$ reduction (PASI 90) and $14 \%$ of patients achieved complete clearance (100\% reduction).

At 22 wk, 88\% of patients achieved PASI 50, 84\% of patients achieved PASI 75, 42\% of patients achieved PASI 90 and $28 \%$ of patients achieved complete clearance.

\subsection{BSA Percent}

BSA percent was reduced from a mean \pm SD of $35.69 \pm 22.44$ before treatment to $25.35 \pm 19.60,11.43 \pm 12.64$, $4.91 \pm 5.55$ and $3.52 \pm 4.94$ at 2, 6, 14 and 22 weeks of treatment, respectively.

Table 2 shows comparison of BSA at each visit with the previous visit with p-values.

The reduction in BSA percent was 28.97\%, 67.97\%, 86.24\% and 90.13\% after 2, 6, 14 and 22 weeks of treatment respectively.

At the end of 22 weeks, the two patients with generalized pustular psoriasis achieved complete clearance.

\subsection{DLQI Score}

DLQI score was reduced from a mean \pm SD of $20.04 \pm 4.68$ before treatment to $14.00 \pm 6.95,7.96 \pm 5.91,4.52$ \pm 4.82 and $3.87 \pm 5.60$ at 2, 6, 14 and 22 weeks of treatment, respectively.

Table 3 shows comparison of DLQI score at each visit with the previous visit with p-values.

The reduction in DLQI score was 30.13\%, 60.27\%, 77.44\% and 80.68\% after 2, 6, 14 and 22 weeks of treatment respectively.

\subsection{Side Effects}

The following side effects were noticed during the period of study. 

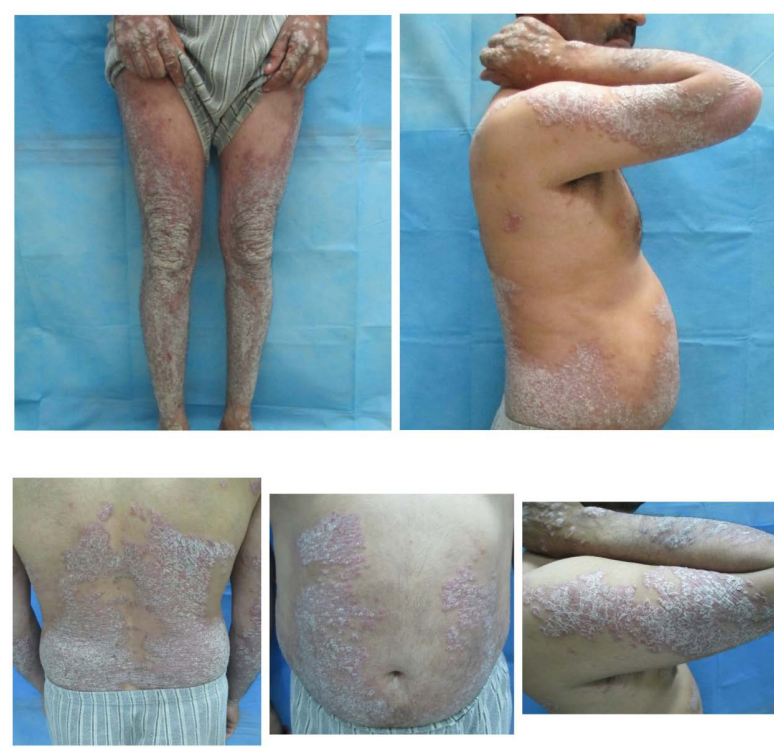

(a)

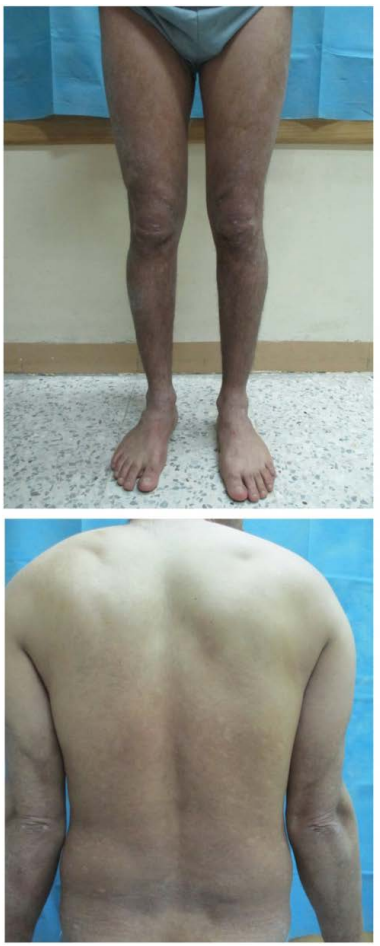

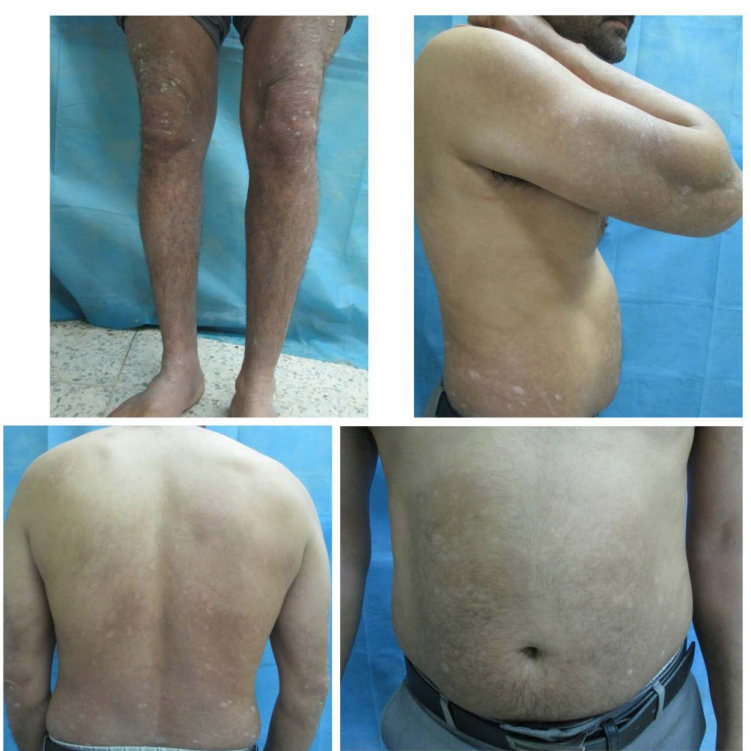

(b)
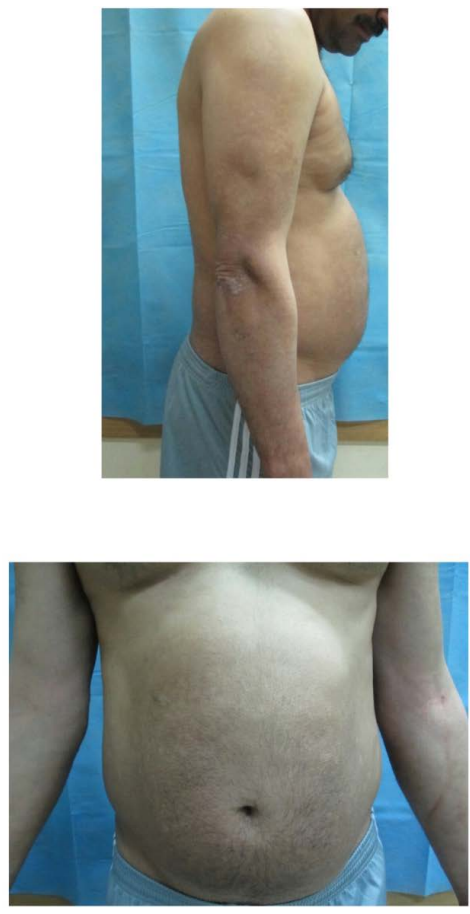

(c)

Figure 2. Thirty-nine year old male with generalized plaque psoriasis for 20 years. (a) Before treatment; (b) after 14 weeks of treatment; (c) after 30 weeks of treatment.

Pruritus was recorded in 2 patients, boils were reported in 1 patient, both were disappeared with continuation of treatment. Alopecia are at a developed in one patient. Four patients had infusion reaction, only in one patient the treatment was stopped. One patient developed new onset psoriatic arthritis and methotrexate was added for this patient.

In 2 patients tuberculin skin test became positive, the treatment was suspended and INH was instituted.

Three patients had relapse during treatment. For the first patient acitretin was added to infliximab and for the second one methotrexate was added. For the third patient infliximab was discontinued because his PASI score 
Table 1. PASI score (mean $\pm \mathrm{SD}$ ) at different weeks with p-values.

\begin{tabular}{|c|c|c|c|}
\hline & \multirow{2}{*}{ Weeks } & PASI score & \multirow[b]{2}{*}{ p-value } \\
\hline & & Mean \pm SD & \\
\hline${ }^{*}$ Pair 1 & $\begin{array}{l}0 \\
2\end{array}$ & $\begin{array}{c}17.41 \pm 8.53 \\
9.75 \pm 6.34\end{array}$ & $<0.000001$ \\
\hline Pair 2 & $\begin{array}{l}2 \\
6\end{array}$ & $\begin{array}{l}9.75 \pm 6.34 \\
4.26 \pm 4.01\end{array}$ & $<0.0001$ \\
\hline Pair 3 & $\begin{array}{c}6 \\
14\end{array}$ & $\begin{array}{l}4.26 \pm 4.01 \\
3.39 \pm 3.46\end{array}$ & $<0.1236{ }^{* *}$ (N.S) \\
\hline Pair 4 & $\begin{array}{l}14 \\
22\end{array}$ & $\begin{array}{l}3.39 \pm 3.46 \\
2.44 \pm 2.68\end{array}$ & $<0.0214$ \\
\hline
\end{tabular}

*Pair1, 2, 3 and 4 compare the results of treatment at subsequent visits. ${ }^{* *}$ (N.S) not significant.

Table 2. BSA (mean \pm SD) at different weeks with p-values.

\begin{tabular}{|c|c|c|c|}
\hline & \multirow{2}{*}{ Weeks } & BSA\% & \multirow{2}{*}{ p-value } \\
\hline & & Mean \pm SD & \\
\hline${ }^{*}$ Pair 1 & $\begin{array}{l}0 \\
2\end{array}$ & $\begin{array}{l}35.69 \pm 22.44 \\
25.35 \pm 19.60\end{array}$ & $<0.00005$ \\
\hline Pair 2 & $\begin{array}{l}2 \\
6\end{array}$ & $\begin{array}{l}25.35 \pm 19.60 \\
11.43 \pm 12.64\end{array}$ & $<0.0003$ \\
\hline Pair 3 & $\begin{array}{c}6 \\
14\end{array}$ & $\begin{array}{c}11.43 \pm 12.64 \\
4.91 \pm 5.55\end{array}$ & $<0.005$ \\
\hline Pair 4 & $\begin{array}{l}14 \\
22\end{array}$ & $\begin{array}{l}4.91 \pm 5.55 \\
3.52 \pm 4.94\end{array}$ & $<0.1105^{* *}$ (N.S) \\
\hline
\end{tabular}

"Pair 1, 2, 3 and 4 compare the results of treatment at subsequent visits. ${ }^{* *}$ (N.S) not significant.

Table 3. DLQI score (mean $\pm \mathrm{SD}$ ) at different weeks with p-values.

\begin{tabular}{|c|c|c|c|}
\hline & \multirow{2}{*}{ Weeks } & DLQI score & \multirow{2}{*}{ p-value } \\
\hline & & Mean \pm SD & \\
\hline${ }^{*}$ Pair 1 & $\begin{array}{l}0 \\
2\end{array}$ & $\begin{array}{l}20.04 \pm 4.68 \\
14.00 \pm 6.95\end{array}$ & $<0.0000001$ \\
\hline Pair 2 & $\begin{array}{l}2 \\
6\end{array}$ & $\begin{array}{c}14.00 \pm 6.95 \\
7.96 \pm 5.91\end{array}$ & $<0.000001$ \\
\hline Pair 3 & $\begin{array}{c}6 \\
14\end{array}$ & $\begin{array}{l}7.96 \pm 5.91 \\
4.52 \pm 4.82\end{array}$ & $<0.001$ \\
\hline Pair 4 & $\begin{array}{l}14 \\
22\end{array}$ & $\begin{array}{l}4.52 \pm 4.82 \\
3.87 \pm 5.60\end{array}$ & $<0.2072{ }^{* *}(\mathrm{~N} . \mathrm{S})$ \\
\hline
\end{tabular}

"Pair 1, 2, 3 and 4 compare the results of treatment at subsequent visits. ${ }^{* *}$ (N.S) not significant.

became more than the baseline.

\section{Discussion}

Biologics are relatively new modalities for treatment of psoriasis [12]. They target different steps in the immunological reactions. [7] Infliximab was approved for the treatment of moderate to severe psoriasis by FDA at 2006 [13].

In Iraq, there is only one center in which infliximab is administrated for the treatment of psoriasis (Medical City Teaching Hospital) and all the data of the patients are presented in this work.

In the present study, PASI score, BSA and DLQI score were significantly improved with the treatment and this improvement begun at the second week of therapy with infliximab. 

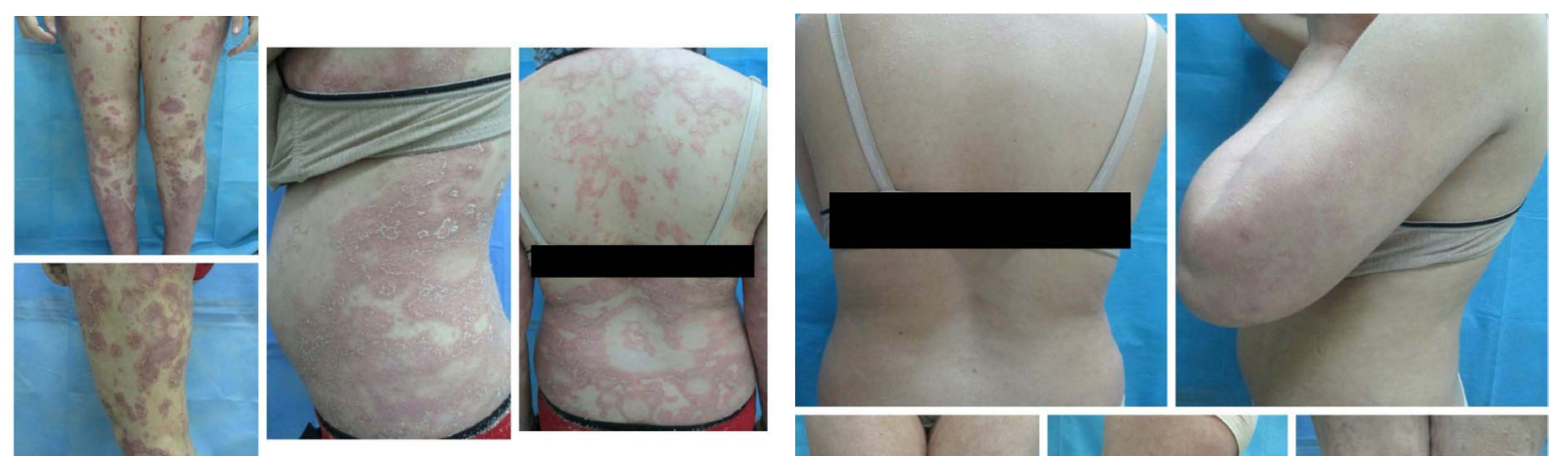

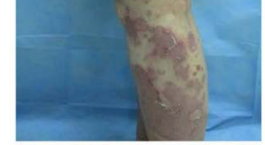

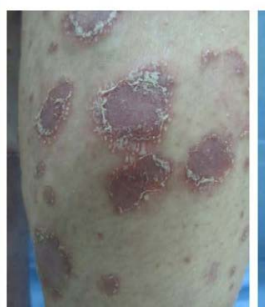

(a)
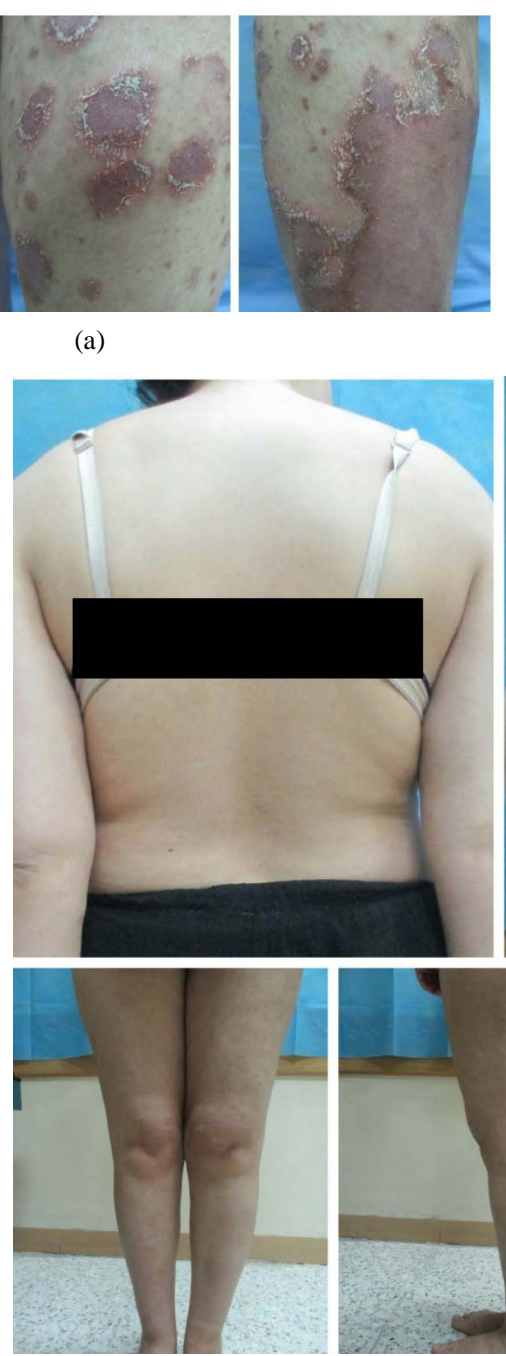

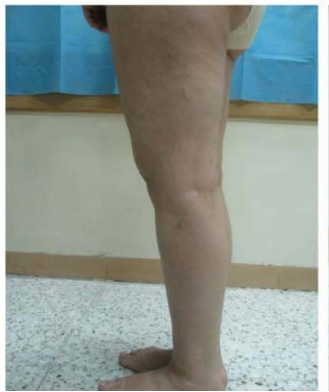

(c)

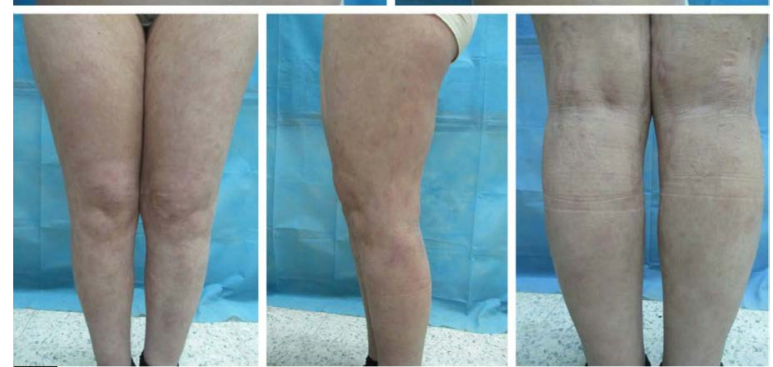

(b)
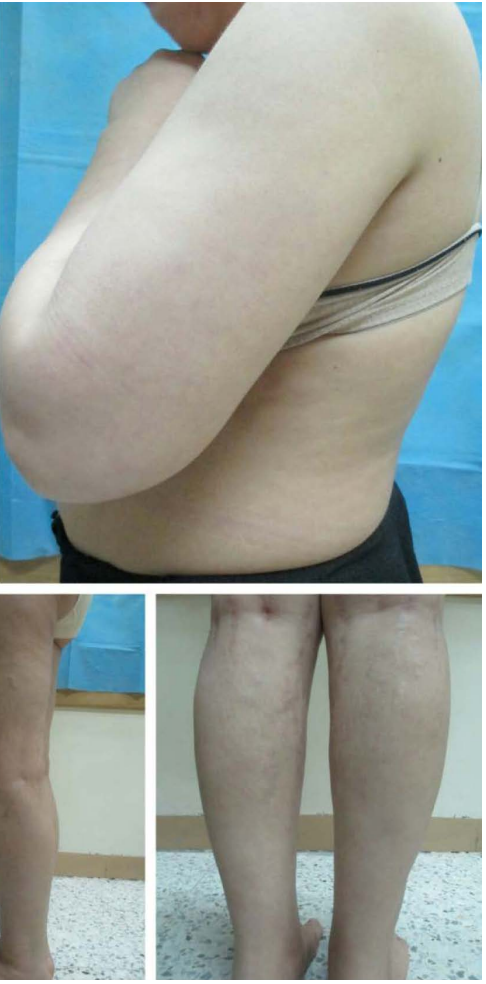

(a) Before treatment; (b) after 14 weeks of treatment; (c) after 30 weeks of treatment.

On comparing our results with other studies on infliximab, Reich et al., [14] found that at week 24 of treatment, 82\% of patients achieved PASI 75 and 58\% achieved PASI 90, while in our study $84 \%$ of patients achieved PASI 75, 42\% achieved PASI 90 and 28\% achieved complete clearance after 22 weeks of treatment.

Smith et al., [15] reported that at week 10, 95\% of patients achieved PASI 50\% and 77\% achieved PASI 75 while in the present study, at week $14,90 \%$ of patients achieved PASI $50,71 \%$ achieved PASI $75,33 \%$ 
achieved PASI $90 \%$ and $14 \%$ of patients achieved complete clearance.

Several workers studied the effect of infliximab on DLQI score in psoriatic patients. Feldman et al., on 2005 [16] showed that DLQI score reduced from a mean \pm SD of $13.2 \pm 7.0$ at baseline to $2.8 \pm 5.0$ at week 10 with a mean percentage improvement of $79.4 \%$, while in the present work DLQI score was reduced from a mean \pm SD of $20.04 \pm 4.68$ at baseline to $4.52 \pm 4.82$ with a mean percentage improvement of $77.4 \%$ at 14 weeks of treatment. All these results are comparable to the results of the present study.

Regarding side effects, the following were reported in different studies: infusion reactions, upper respiratory tract infection, headache, arthralgia, pharyngitis and neoplasms including squamous cell carcinoma and basal cell carcinoma.

In the present study, pruritus, boils, alopecia areata, tuberculin skin test conversion to positive, infusion reactions and new onset psoriatic arthritis were recorded as side effects.

Limitations of the present study include lack of control and small number of patients (23 patients) and this is because it is a single center study. Other limitation include relatively short period of treatment (22 weeks) and this is because infliximab is a new drug in our department. Infliximab is given by infusion and this require a trained nursing staff and beds which are occupied for at least 2 hrs and since the infusion is only given at the morning, few patients can be treated each day.

\section{Conclusion}

In conclusion, infliximab monotherapy seems to be an effective treatment for psoriasis with rapid onset of action and side effects were relatively mild and did not affect the life of the patients.

\section{Disclosure}

This study was an independent study and not funded by any drug companies.

\section{References}

[1] Christophers, E. (2001) Psoriasis-Epidemiology and Clinicalspectrum. Clinical and Experimental Dermatology, 26, 314-320. http://dx.doi.org/10.1046/j.1365-2230.2001.00832.x

[2] Naldi, L.N. (2004) Epidemiology of Psoriasis. Current Drug Target-Inflammation \& Allergy, 3, 121-128. http://dx.doi.org/10.2174/1568010043343958

[3] Gottlieb, A.B. (2003) Clinical Research Helps Elucidate the Role of Tumor Necrosisfactor- $\alpha$ in the Pathogenesis of T1-Mediated Immune Disorders: Use Oftargeted Immunotherapeutics as Pathogenic Probes. Lupus, 12, 190-194. http://dx.doi.org/10.1191/0961203303lu354xx

[4] Krueger, J.G. (2002) The Immunologic Basis for the Treatment of Psoriasis with Newbiologic Agents. Journal of the American Academy of Dermatology, 46, 1-23. http://dx.doi.org/10.1067/mjd.2002.120568

[5] Ali, A. and Ibrahim, A. (2013) Biologic Systemic Therapy for Moderate-to-Severe Psoriasis: A Review. Journal of Taibah University Medical Sciences, 8, 142-150. http://dx.doi.org/10.1016/j.jtumed.2013.09.001

[6] Stephen, K.R. and Joel, M.G. (2012) Immunobiologicals, Cytokines, and Growth Factors in Dermatology. In: Wolf, K., Goldsmith, L.A., Katz, S.I., Gilchrest, B.A., Paller, A.S. and Leffell, D.J., Eds., Fitz Patrick’s Dermatology in General Medicine, 8th Edition, McGraw Hill, New York, 2: 234: 2814-2826.

[7] Breathnach, S.M., Smith, C.H., Chalmers, R.J. and Hay, R.J. (2010) Systemic Therapy. In: Burns, T., Breathnach, S., Cox, N. and Griffiths, C., Eds., Rook's Textbook of Dermatology, 8th Edition, Wiley-Blackwell Publishing Company, Singapore, 4: 74.4 .

[8] Severity and Extent of Psoriasis (Psoriasis Area and Severity Index). http://www.dermnetnz.org/scaly/pasi.html

[9] Krueger, G.G. (2000) Two Considerations for Patients with Psoriasis and Their Clinicians: What Defines Mild, Moderate, and Severe Psoriasis? What Constitutes a Clinically Significant Improvement When Treating Psoriasis? Journal of the American Academy of Dermatology, 43, 281-285. http://dx.doi.org/10.1067/mjd.2000.106374

[10] Quality of Life. Dermatology Life Quality Index. http://www.dermatology.org.uk/quality/dlqi/quality-dlqi.html

[11] Smith, C.H., Anstey, A.V., Barker, J.N., Burden, A.D., Chalmers, R.J. and Chandler, D.A. (2009) British Association of Dermatologists Guidelines for Biological Intervention for Psoriasis 2009. British Journal of Dermatology, 161, 9871019. http://dx.doi.org/10.1111/j.1365-2133.2009.09505.X

[12] Mathur, M., Kedia, S.K. and Chimire, R.B.K. (2011) An Intravenous Biological Therapy for Psoriasis: Infliximab. Journal of College of Medical Sciences-Nepal, 7, 69-72. 
[13] Jeniffer, S. and Robert, E. (2008) Infliximab for the Treatment of Plaque Psoriasis. Biologics, 2, 115-124.

[14] Reich, K. (2005) Infliximab Induction and Maintenance Therapy Formoderate-to-Severe Psoriasis: A Phase III, Multicentre, Double-Blind Trial. Lancet, 366, 1367-1374. http://dx.doi.org/10.1016/S0140-6736(05)67566-6

[15] Smith, C.H., Jackson, K., Bashir, S.J., Perez, A., Chew, A.L., Powell, A.M., Wain, M. and Barker, J. (2006) Infliximab for Severe, Treatment-Resistant Psoriasis: A Prospective, Open-Label Study. British Journal of Dermatology, 155, 160-169. http://dx.doi.org/10.1111/j.1365-2133.2006.07316.x

[16] Feldman, S.R., Gordon, K.B. and Bala, M. (2005) Infliximab Treatment Results in Significant Improvement in the Quality of Life of Patients with Severe Psoriasis: A Double-Blind Placebo-Controlled Trial. British Journal of Dermatology, 152, 954-960. http://dx.doi.org/10.1111/j.1365-2133.2005.06510.x 